J. Lake Sci. (湖泊科学), 2011, 23(2): 239-245

http: //www. jlakes. org. E-mail : jlakes@niglas.ac.cn

(C) 2011 by Journal of Lake Sciences

\title{
长江中游湖泊沿岸带的底栖藻类群落结构特征”
}

\author{
裴国风 ${ }^{1}$, 刘国祥 ${ }^{2 * *}$ \\ (1: 中南民族大学微生物与生物转化实验室,武汉 430074) \\ (2: 中国科学院水生生物研究所, 武汉 430072)
}

摘 要: 测定和分析湖北省 21 个浅水湖泊沿岸带底栖澡类的现存量, 底栖硅藻的种类组成、细胞密度、多样性指数及其群 落结构特征, 并结合理化指标对水质状况进行评价. 结果表明: 调查期间, 不同湖泊底栖藻类的现存量和底栖硅藻细胞 密度分别介于 $1.01-40.82 \mu \mathrm{g} / \mathrm{cm}^{2}$ 和 $0.09 \times 10^{6}-14.20 \times 10^{6} \mathrm{cells} / \mathrm{cm}^{2}$ 之间, 它们在所研究的富营养化湖泊中的含量均 相对较高. 在发现的 181 种(变种) 底栖硅藻中, 极细微曲壳藻分布广泛, 是中营养、中-富营养湖泊的绝对优势种或主要 优势种之一. TWINSPAN 和 DCA 分析结果显示这些湖泊样点被分成 3 组, 第一组中-富营养型湖泊的主要优势种是曲壳 藻属的一些种类; 第二组中营养湖泊同时存在分布相对均匀的多个优势种; 第三组主要是城区富营养湖泊. 南湖处于超 富营养水平,小形异极藻占绝对优势 (相对丰富度为 $43 \%$ ).

关键词: 底栖藻类; 群落结构; 现存量; 硅藻; 优势种;沿岸带; 长江中游

\section{Community structure characters of benthic algae community on littoral zone of the lakes in the middle reaches of Yangtze River}

\section{PEI Guofeng ${ }^{1} \&$ LIU Guoxiang ${ }^{2}$}

(1: Laboratory of Microorganism and Biotransformation, South-Central University for Nationalities, Wuhan 430074, P. R. China)

(2: Institute of Hydrobiology, Chinese Academy of Sciences, Wuhan 430072, P. R. China)

Abstract: Species composition, cell density, Shannon-Weaver diversity index, community structures of benthic diatoms and standing crops of benthic algae were investigated in the littoral zone of 21 shallow lakes in Hubei Province, and the water quality was evaluated combined with chemical parameters. The standing crops (Chl. a) of benthic algae and the density of benthic diatoms, with the range of $1.01-40.82 \mu \mathrm{g} / \mathrm{cm}^{2}$ and $0.09 \times 10^{6}-14.20 \times 10^{6}$ cells $/ \mathrm{cm}^{2}$, respectively, exhibited higher values in eutrophic lakes during the studying period. Among the 181 taxa (variety) of benthic diatom observed, Achnanthes minutissima distributed widely and was absolutely dominant or sub-dominant species in mesotrophic and meso-eutrophic lakes. The results of two-way indicator species analysis and detrended correspondence analysis catalogued these lakes into three groups: the dominant species were taxa of Achnanthes genus in meso-eutrophic lakes of the first group; several dominant species existed at the same time in mesotrophic lake of the second group; the third group were the city eutrophic lakes. Nanhu was hyper-eutrophic lake, Gomphonema parvulum was dominant indictor (43\% of relative abundance).

Keywords: Benthic algae; community structure; standing crops; diatom; dominant species ; littoral zone; middle reaches of Yangtze River

底栖藻类是浅水湖泊生态系统的重要初级生产者和水化学调节者, 维持着生态系统的多样性, 在能量 转换和物质传递方面起着重要的作用 ${ }^{[1]}$, 同时, 底栖藻类对降低浅水水体的富营养化水平, 增加水体透明 度, 稳定生态系统和促进水生高等植物的恢复, 降低蓝藻水华暴发的频率等也具有十分重要的作用 ${ }^{[2]}$. 长江 中下游地区分布着众多的淡水湖泊, 其中大多数都是中小型的浅水湖泊, 具有面积大、水浅、水力滞留时间

* 国家自然科学基金项目 (30970550)资助. 2010-05-24 收稿;2010-07-05 收修改稿. 裴国凤,女,1969 年生,博 士,副教授;E-mail: peigf@ mail. scuec. edu.cn.

** 通讯作者;E-mail: liugx@ ihb. ac. cn. 
较短, 水位变动大、沿岸带占湖泊面积的比例较大及人类活动干扰强度大等特点. 20 世纪中叶开始的大规 模围湖造田和 80 年代兴起的围网养鱼, 破坏了湖泊水生生物的栖息生境, 水生生物群落发生了极大的变 化 ${ }^{[3]}$; 大量农业肥料的使用, 生活垃圾及动植物残体等营养物质的输人使大多数湖泊逐渐富营养化, 水生高 等植物已经逐渐消失, 但在其沿岸带依然有各种底栖藻类群落, 比如一些丝状绿藻、硅藻等, 已有学者对长 江中下游地区湖泊的沉积物硅藻进行了相关报道 ${ }^{[4-5]}$. 为全面了解长江中游底栖藻类的群落结构特征, 本研 究对湖北省长江中游地区的 21 个代表性湖泊沿岸带底栖藻类的现存量进行初步的调查, 系统分析底栖硅 藻的种类组成、生物多样性特点及其群落结构特征, 探讨湖泊富营养化与底栖硅藻之间的关系, 为进一步利 用底栖硅藻来定量评价水体环境质量提供科学依据.

\section{1 材料与方法}

\section{1 样品的采集和水体理化指标的测定}

于 2006 年的春季 (4-5 月份), 对随机选择的梁子湖、牛山湖、后湖、鲁湖、团墩湖、三湖连江、密泉湖、陆 水、保安湖、磁湖、斧头湖、大治湖、大源湖、太白湖、汤逊湖、东湖一水果湖、东湖一牛巢湖、南湖和紫阳湖进行 样品的采集工作, 在这些湖泊沿岸带 $20-40 \mathrm{~cm}$ 左右深的水中, 随机选取 $3-5$ 个样点, 采集该区域主要天然 基质 (如各种石块或沉水植物的叶片) 上的底栖藻类样品, 置于冰盒内; 与此同时, 在每个样点取 $1 \mathrm{~L}$ 水样带 回实验室, 参照国标相关方法 ${ }^{[6]}$ 测定主要的水化学指标, 数据分析中每个湖泊的数据为各湖泊所选样点的 平均值.

\section{2 样品的处理}

用硬毛刷将一定面积的天然基质表面上的底栖藻类样品刷于蒸馏水中, 定量到 $200 \mathrm{ml}$, 分成两份: 一份 用 90\% 的丙酮溶液提取叶绿素 (Chl. a、Chl. b、Chl. c), 测定 470、630、647、664 和 750nm 波长的吸光值, 根 据吸光值计算藻样的 Chl. a 含量, 方法参照 Steinman 等 ${ }^{[7]}$; 另一份保存于 $5 \%$ 的福尔马林溶液中, 用于底栖 硅藻的种类鉴定和定量分析, 硅藻的预处理参照 Barber \& Haworth ${ }^{[8]}$, 取 $1 \mathrm{ml}$ 藻样加酸处理, 洗涤除砂后, 再 取定量样品和中性树胶混匀后, 置于盖玻片上, 制作硅藻永久制片, 在光学显微镜 $(1000 \times)$ 下, 用视野法对 硅藻的永久制片进行计数, 每片计数不得少于 500 个. 藻类的鉴定参照 Krammer \& Lange-Bertalot ${ }^{[9]}$.

\section{3 数据的处理及统计分析}

Shannon-Weaver 指数 $\left(H^{\prime}\right): H^{\prime}=-\sum P_{i} \log _{2} P_{i}\left(P_{i}=N_{i} / N\right)$. 式中: $\mathrm{N}$ 为同一样品中的个体总数, $N_{i}$ 为 第 $i$ 种的个体数. 使用双向指示物种分析 (Two-Way Indictor Species Analysis, TWINSPAN) 和除趋势对应分 析 (Detrended Correspondence Analysis, DCA), 前者确定样方或物种的类别, 后者确定样方或种类的分类数 目. 用 DECORANA (Version 1.0) 对所有湖泊底栖硅藻群落的相对丰富度数据和硅藻绝对数量对数值进行 TWINSPAN 分析, 在用软件 $\mathrm{CANOCO}^{[10]}$ 进行 DCA 分析前, 为了消除物种丰富度极端值对分类得分的影响, 先对数据进行对数转换, 并降低稀有物种的权重, 以便使研究主要集中在丰富度高的物种上. 利用 SPSS 13.10 进行数据统计和相关分析.

\section{2 结果与分析}

\section{1 水体理化指标}

研究期间, 21 个湖泊样点的总磷范围是 $0.011-0.786 \mathrm{mg} / \mathrm{L}$, 大源湖和南湖样点的总磷浓度分别最低 和最高; 总氮是 $0.269-14.061 \mathrm{mg} / \mathrm{L}\left(\right.$ 表 1). 依据 Lowe ${ }^{[11]}$ 等的标准, 这些湖泊的营养状况不同, 中营养水 平的湖泊有梁子湖、西凉湖、陆水和斧头湖; 牛巢湖、鲁湖、牛山湖、三湖连江、汤逊湖、保安湖、梁子湖鱼 塘、太白湖、大冶湖和大源湖处于中-富营养水平; 水果湖、后湖、团墩湖、密泉湖、紫阳湖、磁湖和南湖为富 (超富) 营养水平. 水温大约在 $20-24^{\circ} \mathrm{C}$ 之间; 除后湖、三湖连江、太白湖和斧头湖外, 其它湖泊样点的 $\mathrm{pH}$ 值均大于 8 ; 武汉市城区几个湖泊的电导率相对较高, 大于 $500 \mu \mathrm{S} / \mathrm{cm}^{2}$, 南湖样点的 TP、TN 和电导率均高 于其它湖泊.

\section{2 底栖藻类的现存量 ( Chl. a) 和底栖硅藻的结构特征}

调查期间, 各湖泊底栖藻类的现存量之间的差异非常大 (表 1), 最高为水果湖 ( $40.82 \mu \mathrm{g} / \mathrm{cm}^{2}$ ), 最低汤 
逊湖 ( $\left.1.01 \mu \mathrm{g} / \mathrm{cm}^{2}\right)$, 其中南湖、水果湖和紫阳湖等富营养湖泊的现存量较高, 均大于 $13.72 \mu \mathrm{g} / \mathrm{cm}^{2}$, 其次是 大治湖、太白湖、三湖连江和牛巢湖的现存量是 $7.97-9.92 \mu \mathrm{g} / \mathrm{cm}^{2}$. 这些湖泊的底栖硅藻密度在 $0.09 \times$ $10^{6}-14.20 \times 10^{6} \mathrm{cells} / \mathrm{cm}^{2}$ 之间, 其中富营养湖泊的硅藻密度比中-富营养和中营养湖泊高, 如硅藻密度最高 的水果湖样点可达 $1.4 \times 10^{7} \mathrm{cells} / \mathrm{cm}^{2}$, 斧头湖最低仅为 $9.0 \times 10^{4} \mathrm{cells} / \mathrm{cm}^{2}$. 水果湖、牛巢湖、梁子湖、团墩湖、 梁子湖鱼塘、磁湖、大治湖和汤逊湖的 Shannon-Weaver 多样性指数和种类数均较高, 分别大于 2.35 和 30 (表 $1)$. 在这些湖泊中, 南湖的多样性指数和种类数均为最低. 这表明在中营养和富营养湖泊中, 底栖硅藻的种 类数和多样性指数相对较高, 而在重度富营养化湖泊 (如南湖), 种类数少、多样性指数低.

表 121 个湖泊样点的水化学指标均值以及底栖藻类现存量和硅藻的细胞密度、Shannon-Weaver 指数、种类数

Tab. 1 Mean values of water chemistry characters, biomass of benthic algae and diatoms density,

Shannon-Weaver diversity index, species numbers in 21 lakes

\begin{tabular}{|c|c|c|c|c|c|c|c|c|c|}
\hline $\begin{array}{c}\text { 湖泊名称 } \\
\text { 及编号 }\end{array}$ & $\begin{array}{c}\mathrm{TN} \\
(\mathrm{mg} / \mathrm{L})\end{array}$ & $\begin{array}{c}\mathrm{TP} \\
(\mathrm{mg} / \mathrm{L})\end{array}$ & $\mathrm{pH}$ & 温度 $\left({ }^{\circ} \mathrm{C}\right.$ ) & $\begin{array}{c}\text { 电导率 } \\
\left(\mu \mathrm{S} / \mathrm{cm}^{2}\right)\end{array}$ & $\begin{array}{c}\text { 现存量 } \\
\left(\mu \mathrm{g} / \mathrm{cm}^{2}\right)\end{array}$ & $\begin{array}{c}\text { 硅藻密度 } \\
\left(\times 10^{6} \text { cells }\right. \\
\left./ \mathrm{cm}^{2}\right)\end{array}$ & $\begin{array}{l}\text { Shannon- } \\
\text { Weaver 多 } \\
\text { 样性指数 }\end{array}$ & 种类数 \\
\hline 南湖 1 & $14.061 \pm 2.215$ & $0.786 \pm 0.018$ & $8.2 \pm 0.5$ & $21.1 \pm 1.2$ & $636 \pm 68$ & $21.50 \pm 2.21$ & $3.74 \pm 0.60$ & $1.32 \pm 0.04$ & $12 \pm 3$ \\
\hline 水果湖 2 & $1.273 \pm 0.089$ & $0.130 \pm 0.010$ & $8.5 \pm 0.4$ & $21.9 \pm 0.9$ & $618 \pm 52$ & $40.82 \pm 5.36$ & $14.20 \pm 1.60$ & $2.40 \pm 0.06$ & $32 \pm 4$ \\
\hline 牛巢湖 3 & $0.808 \pm 0.009$ & $0.024 \pm 0.004$ & $8.3 \pm 0.4$ & $21.4 \pm 1.5$ & $525 \pm 36$ & $7.97 \pm 0.89$ & $9.04 \pm 0.65$ & $2.36 \pm 0.08$ & $36 \pm 5$ \\
\hline 梁子湖 4 & $0.269 \pm 0.005$ & $0.024 \pm 0.003$ & $8.2 \pm 0.3$ & $21.6 \pm 0.4$ & $255 \pm 21$ & $2.20 \pm 0.09$ & $0.60 \pm 0.02$ & $2.90 \pm 0.04$ & $32 \pm 5$ \\
\hline 牛山湖 5 & $0.379 \pm 0.008$ & $0.028 \pm 0.004$ & $8.2 \pm 0.4$ & $21.5 \pm 0.8$ & $280 \pm 33$ & $2.66 \pm 0.08$ & $0.72 \pm 0.02$ & $2.11 \pm 0.06$ & $18 \pm 2$ \\
\hline 后湖 6 & $1.050 \pm 0.021$ & $0.066 \pm 0.008$ & $7.6 \pm 0.6$ & $20.0 \pm 0.8$ & $314 \pm 42$ & $6.51 \pm 0.10$ & $2.13 \pm 0.43$ & $1.56 \pm 0.02$ & $18 \pm 1$ \\
\hline 鲁湖 7 & $0.306 \pm 0.008$ & $0.015 \pm 0.001$ & $8.4 \pm 0.5$ & $19.9 \pm 1.1$ & $214 \pm 20$ & $4.03 \pm 0.08$ & $0.70 \pm 0.08$ & $1.34 \pm 0.01$ & $28 \pm 2$ \\
\hline 团墩湖 8 & $0.741 \pm 0.010$ & $0.028 \pm 0.003$ & $8.1 \pm 0.7$ & $20.3 \pm 1.5$ & $174 \pm 23$ & $4.18 \pm 0.07$ & $1.96 \pm 0.32$ & $3.12 \pm 0.09$ & $45 \pm 4$ \\
\hline 三湖连江 9 & $2.848 \pm 0.126$ & $0.019 \pm 0.002$ & & & & & \pm 0.46 & $1.70 \pm 0.03$ & $42 \pm 5$ \\
\hline 密泉湖 10 & $0.615 \pm 0.011$ & $0.053 \pm 0.006$ & $8.3 \pm 0.8$ & $20.1 \pm 1.6$ & $240 \pm 40$ & $6.22 \pm 0.80$ & $3.01 \pm 0.22$ & $1.82 \pm 0.01$ & $23 \pm 2$ \\
\hline 陆水 11 & $0.908 \pm 0.015$ & $0.043 \pm 0.003$ & $8.5 \pm 0.6$ & $19.8 \pm 1.0$ & $173 \pm 20$ & $2.62 \pm 0.10$ & $1.63 \pm 0.08$ & $2.25 \pm 0.04$ & $29 \pm 3$ \\
\hline 紫阳湖 12 & $1.230 \pm 0.045$ & $0.156 \pm 0.011$ & $8.6 \pm 0.9$ & $20.7 \pm 1.6$ & $505 \pm 86$ & $19.78 \pm 1.68$ & $3.07 \pm 0.42$ & $2.35 \pm 0.03$ & $33 \pm 4$ \\
\hline 保安湖 13 & $0.735 \pm 0.011$ & $0.027 \pm 0.004$ & $8.5 \pm 0.5$ & $24.5 \pm 1.2$ & $544 \pm 79$ & $13.72 \pm 1.45$ & $6.00 \pm 0.81$ & $1.89 \pm 0.02$ & $25 \pm 2$ \\
\hline 梁子湖鱼塘 14 & $0.461 \pm 0.008$ & $0.047 \pm 0.005$ & $8.2 \pm 0.9$ & $24.1 \pm 1.8$ & $240 \pm 36$ & $2.34 \pm 0.08$ & $0.89 \pm 0.05$ & $2.35 \pm 0.06$ & $31 \pm 3$ \\
\hline 磁湖 15 & $1.990 \pm 0.056$ & $0.072 \pm 0.005$ & $8.3 \pm 0.6$ & $20.9 \pm 0.9$ & $513 \pm 68$ & $6.57 \pm 0.30$ & $1.13 \pm 0.22$ & $2.66 \pm 0.05$ & $30 \pm 3$ \\
\hline 太白湖 16 & $0.900 \pm 0.013$ & $0.027 \pm 0.002$ & $7.9 \pm 0.5$ & $21.5 \pm 1.0$ & $337 \pm 49$ & $9.92 \pm 1.26$ & $1.90 \pm 0.06$ & $1.74 \pm 0.02$ & $22 \pm 2$ \\
\hline 大源湖 17 & $0.891 \pm 0.010$ & $0.011 \pm 0.001$ & $8.8 \pm 0.7$ & $24.3 \pm 1.3$ & $220 \pm 35$ & $2.82 \pm 0.09$ & $0.51 \pm 0.01$ & $2.16 \pm 0.04$ & $28 \pm 3$ \\
\hline 西凉湖 18 & $0.497 \pm 0.009$ & $0.035 \pm 0.003$ & $8.2 \pm 0.5$ & $22.7 \pm 1.4$ & $228 \pm 30$ & $4.52 \pm 0.16$ & $0.27 \pm 0.03$ & $1.87 \pm 0.03$ & $29 \pm 3$ \\
\hline 斧头湖 19 & $0.433 \pm 0.008$ & $0.064 \pm 0.007$ & $7.8 \pm 0.2$ & $21.8 \pm 1.0$ & $296 \pm 46$ & $2.45 \pm 0.08$ & $0.09 \pm 0.01$ & $1.95 \pm 0.02$ & $13 \pm 1$ \\
\hline 大冶湖 20 & $0.369 \pm 0.005$ & $0.023 \pm 0.001$ & $8.3 \pm 0.6$ & $23.3 \pm 1.2$ & $390 \pm 35$ & $8.94 \pm 1.10$ & $0.86 \pm 0.02$ & $2.89 \pm 0.06$ & $36 \pm 4$ \\
\hline 汤逊湖 21 & $0.935 \pm 0.007$ & $0.059 \pm 0.008$ & $8.1 \pm 0.8$ & $22.9 \pm 0.9$ & $470 \pm 40$ & $1.01 \pm 0.06$ & $0.15 \pm 0.01$ & $2.82 \pm 0.04$ & $35 \pm 3$ \\
\hline
\end{tabular}

\section{3 底栖硅藻群落的优势种分布及样点的空间格局特征}

在 21 个湖泊样点中, 发现底栖硅藻 181 种 (含变种), 分布在这些湖泊中的 11 种常见底栖硅藻的相对 丰富度表明(图 1), 比索曲壳藻(Achnanthes biasoletti)、克利夫曲壳藻 (Achnanthes clevei)、极细微曲壳藻 (Achnanthes minutissima) 在中营养和中-富营养湖泊中的相对丰富度较高, 变异直链藻 (Melosira varians)、爆裂针 杆藻 (Fragilaria rumpens) 、肘状针杆藻 (Synedra ulna) 、禹形双眉藻 (Amphora pediculus) 、小形异极藻 (Gomphonema parvulum)、隐头舟形藻 (Navicula cryptocephala)、嗜盐舟形藻 (Navicula halophila)、莱因哈德舟 形藻 (Navicula reinhardtiana) 等主要出现在富营养湖泊中, 其中变异直链藻和小形异极藻分别在水果湖和南 湖的相对百分含量很高(大于 $35 \%$ ).

除趋势对应分析 (DCA) 的结果与 TWINSPAN 相吻合, 这三个组在第一轴上从左向右得到很好的分化 (图 2), 排序图较好地反映了各组在排序空间的分布关系. 21 个湖泊样点依据底栖硅藻的组成差异分成 3 组:第一组包括大源湖、太白湖、磁湖、三湖连江、密泉湖、团墩湖、鲁湖、后湖、梁子湖鱼塘和牛巢湖; 西凉湖、 陆水、斧头湖和梁子湖组成第二组; 第三组由紫阳湖、保安湖、大治湖、牛山湖、水果湖和汤逊湖构成; 南湖样 点被排除在各组之外. 


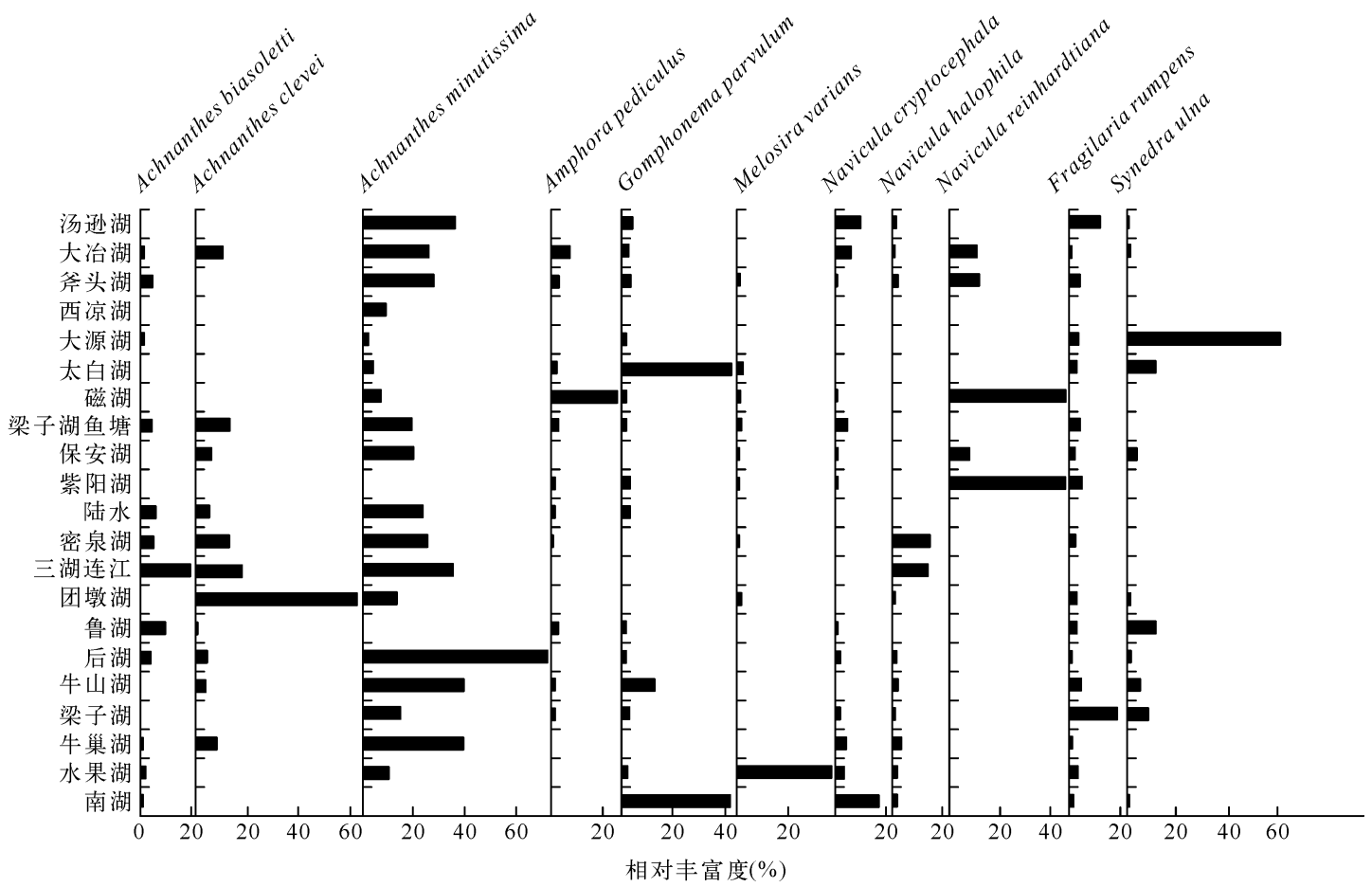

图 121 个湖泊常见底栖硅藻的相对丰富度

Fig. 1 Relative abundance of the most benthic diatoms in 21 lakes

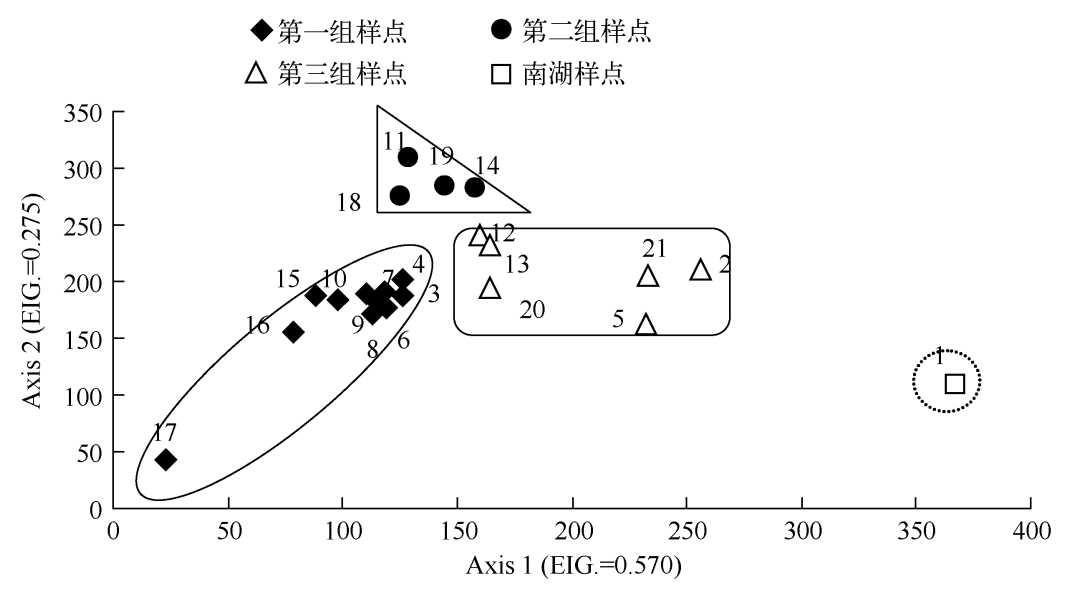

图 221 个湖泊底栖硅藻丰富度的 DCA 排序散点图

Fig. 2 Detrended correspondence analysis ordination diagram of 21 lakes based on abundance of benthic diatoms

第一组的 10 个湖泊具有相似的地理环境, 是典型的浅水平原型湖泊, 湖盆平浅, 水位变动大, 冬季易形 成枯水位, 夏季为丰水期. 其中, 在大源湖、太白湖和磁湖样点的底栖硅藻群落都存在绝对优势种, 例如, 大 源湖的总磷含量最低, 以广布性种类肘状针杆藻占绝对优势, 相对丰富度高达 $59.8 \%$, 太白湖的极小异极藻 占 $42.16 \%$, 磁湖的莱因哈德舟形藻和蛗形双眉藻的相对丰富度分别是 $46.36 \%$ 和 $24.93 \%$, 而在三湖连江、 牛巢湖、密泉湖、团墩湖、鲁湖、后湖和梁子湖鱼塘样点, 观察发现底栖藻类群落中硅藻的相对比率一般高于 
绿藻; 其中, 底栖硅藻群落的组成具有明显的共同特征, 即优势种主要是曲壳藻属 (Achnanthes) 的一些种类, 它们在后湖、密泉湖、团墩湖和三湖连江的相对丰富度高达 $70 \%$ 以上,例如极细微曲壳藻是这些湖泊的共同 优势种, 其相对丰富度在后湖最高达到 71.72\%, 磁湖最低也有 $6.87 \%$ (图 1). 极细微曲壳藻是一个广布性 的广幅营养型种 ${ }^{[9]}, \mathrm{pH}$ 值的耐受范围较宽, 但该种类在超富营养型湖泊的相对丰富度较低或未观察到.

第二组的四个湖泊均为中营养水平, 分布在这几个湖泊的底栖硅藻群落具有共同的特点, 即同时存在 多个优势种, 且优势种的分布相对均匀, 没有相对丰富度很高的绝对优势种, 其中, 极细微曲壳藻是这些湖 泊 (西凉湖除外) 的主要优势种之一, 相对丰富度的范围是 $15 \%-27 \%$, 此外,陆水和斧头湖的主要优势种还 有莱因哈德舟形藻; 梁子湖的是污染敏感性种爆裂针杆藻和极小桥弯藻; 西凉湖比较特殊, 我们到达的采样 点没有方便带回实验室分析的硬基质, 湖底为软基质淤泥, 水体的总磷浓度和电导率相对较低, 水草生长茂 盛,该湖采集的底栖硅藻样品主要是苦草上附着生长的附植硅藻, 主要是卵形藻属 (Cocconeis) 的一些种类, 它们的相对丰富度总和高达 $77 \%$. 优势种扁圆卵形藻线形变种 (Cocconeis placentula var. lineate) 以面着生方 式附着在高等水生植物和其他大型丝状藻类上, 是一个广布性的广幅营养性种, 多生长在寡营养和中富营 养水体.

第三组的湖泊多数为城区湖泊, 电导率都较高, 极细微曲壳藻在这几个湖泊都有分布, 是牛山湖和汤逊 湖的主要优势种, 其相对丰富度超过 $35 \%$, 威蓝色双眉藻 (Amphora veneta) 和隐头舟形藻也分别是这两个湖 泊的优势种. 紫阳湖的绝对优势种 (相对丰富度为 $54 \%$ ) 是莱因哈德舟形藻, 也是大冶湖和保安湖的优势种 类,该种为喜盐种类. 牛巢湖和水果湖是东湖的两个独立湖区, 前者的部分区域有水草生长, 水化学指标略 优于后者 (表 1), 虽然极细微曲壳藻在两个湖区均有分布, 但相对丰富度不同, 牛巢湖为 $39 \%$, 明显高于水 果湖的 $10 \%$, 变异直链藻是水果湖的绝对优势种 (相对丰富度为 38\%), 属广幅营养型的普生性种类, 也是 广布性的耐污染种类,水果湖的硅藻密度明显高于其他湖泊 (表 1 ).

南湖是城市湖泊, 周围人口密集, 生活污水排人引起的点源污染特别严重, TN、TP 和电导率分别是 $14.06 \mathrm{mg} / \mathrm{L} 、 0.79 \mathrm{mg} / \mathrm{L}$ 和 $636 \mu \mathrm{S} / \mathrm{cm}^{2}$, 这些参数在所研究的 21 个湖泊中最高. 底栖藻类群落中的绿藻生物 量较高, 主要以一种鞘藻 (Oedogonium sp.) 为优势种类; 而组成硅藻群落的物种较少, 主要优势种是小形异 极藻 (相对丰富度为 $43 \%$ ) 和运动型的细粒舟形藻 (Navicula atomus, 占 25\% )、嗜盐舟形藻 (占 $16 \%$ ); 与其 他湖泊明显不同. 这些优势种虽属广布性种,但通常出现在营养水平相当高的水体中.

\section{3 讨论}

\section{1 底栖藻类群落的现存量、硅藻群落结构特征与营养状况的关系}

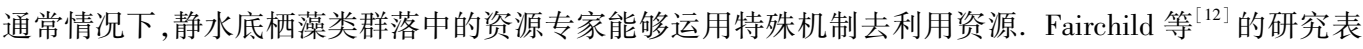
明极细微曲壳藻是磷专家, 能够在磷受到限制的情况下生长旺盛, 它是 TP 为 $0.024-0.064 \mathrm{mg} / \mathrm{L}$ 的绝大多 数长江中游湖泊中的主要优势种, 但在 TP 高于此范围的湖泊中, 其相对丰富度并不高, 不同底栖藻类利用 资源的独特机制可能也是本研究中不少富营养化湖泊存在绝对优势种的原因之一. 研究表明许多底栖硅藻 对水体营养浓度并不直接响应, 像针杆藻属 (Synedra) 的一些种类主要受湖水透光条件影响, 而受营养的影 响较小 ${ }^{[13]}$, 调查期间, Synedra 属的种类在这些湖泊中的分布也没有明显表现出受到营养的影响; 扁圆卵形 藻 (Cocconeis placentula) 在受污染与不受污染的湖泊中均有分布, 对于这种不敏感性, Lorch \& Ottow ${ }^{[14]}$ 认为, 这种硅藻并非真的对水质不敏感, 而可能是由于这种硅藻所依附的基质一大型的水生植物是一种天然的 “营养过滤装置”, 屏蔽了水中有机物对硅藻的直接作用, 所以它在水草生长茂盛的中营养西凉湖占绝对优 势. 扁圆卵形藻对环境的强适应力也归因于其着生方式及生理特性, 其面着生方式至少有如下优点: 不易受 无脊椎动物摄食、不易从基质上脱落、可吸收活水草分泌的营养物 ${ }^{[15]}$.

综合分析发现中一富营养型湖泊底栖硅藻的多样性指数和种类丰富度值较高, 其它研究也证明了这一 结论 ${ }^{[16]}$. 就所研究湖泊的硅藻种类多样性来说, 它和湖泊的营养状况缺乏相关性. 事实上, 多样性指数会在 较高或者较低的营养水平下降低 ${ }^{[17]}$. Stevenson 等 ${ }^{[15]}$ 指出, 就一个生态系统来说, 如果原来所具有的种类多 样性较高, 则此系统受到压力时, 往往是降低多样性; 但如果原来多样性很低, 则增加水体营养所产生的效 应往往会提高这个系统的多样性. Huston ${ }^{[18]}$ 提出这样一个假说, 即随着生态系统中营养物质浓度的增加,往 
往使一个生物群落的多样性与生产力均增加, 然而随着营养物继续增加, 将抑制种类的增加, 多样性与生产 力均下降, 这说明多样性指数本身并不适合用来评价环境, 因为除污染外的其它因素也能影响硅藻群落的 结构 ${ }^{[15]}$.

对于浮游藻类来说, 通常可以根据一个湖泊中总磷的含量来预测其生物量. 然而, Cattaneo ${ }^{[19]}$ 发现底栖 藻类的生物量和总磷的含量没有很好的相关性, 这和本研究结果是一致的, 其原因可能是底栖藻类和浮游 藻类之间对营养和光照存在着竞争. 在一定营养范围内, 各湖泊底栖藻类的生物量随着湖泊营养水平的增 加而增加, 但是藻类生长的营养限制并不随着湖泊营养的增加而减少 ${ }^{[15]}$, 所以营养水平最高的南湖底栖藻 类的生物量并不是最高的. 此外, 水体环境中化学物质的改变引起底栖藻类群落的改变也可能被其他因素 修改或者掩盖. 例如, 点源营养能够导致底栖藻类生产力的增加, 而初级生产者向牧食者的快速转移使得底 栖藻类生物量的增加并不明显 ${ }^{[11]}$.

\section{2 影响底栖硅藻群落分布格局的环境因素}

DCA 分析主要以群落的数量特征为依据, 分类结果比较客观, 从分类结果可以归纳总结出每类群落的 环境特点, 从而反映群落在适应环境方面的相似性. 本研究选择的 21 个湖泊代表了范围较广的湖泊特征: 受污染较轻、水质相对较好的中营养湖泊 (梁子湖), 有机污染重、营养水平较高的富营养湖泊和污染严重、 混浊度高的超富营养湖泊. Sommer ${ }^{[20]}$ 的研究表明众多因子交互作用共同决定藻类的分布, 影响藻类分布的 环境因子很多, 如微生境的营养水平、电导率、基质类型、生物间关系等, 例如, 董旭辉等 ${ }^{[5]}$ 报道了长江中下 游地区 45 个湖泊表层沉积硅藻属种分布及其对总磷指标的生态学特征, 证实总磷是所有环境指标中影响 该区硅藻分布最显著重要的变量, 然而, Guzkowska and Gasse ${ }^{[21]}$ 发现硬度和电导率是影响市区型和土壤型 湖泊群落变化的主要因子, 营养是第二因子, 本研究中电导率高的湖泊被分在了 DCA 的第三个组. 分析本 研究结果发现硅藻密度和多样性与湖泊的营养参数之间缺乏相关性 (相关系数为 $0.41, P>0.05$ ). 究其可 能原因, 首先是这些浅水湖泊的湖盆平浅、水位变动大、底泥肥厚, 再加上湖沿岸带长, 易接纳较多地表径流 带进的外源性营养, 这样的水体参数会在短时间内发生极大的变化 ${ }^{[22]}$, 其次在有些湖泊中是绿藻占优势. 例 如, 调查期间三分之一湖泊中绿藻生物量的相对比例高于硅藻, 所以仅以硅藻作为营养状况的参考模式可 能并不十分理想. 特别是在软藻 “soft algae” 生物量的相对比例高于硅藻时, 应该将两者综合起来, 分析它们 与湖泊营养状况的关系. 而底栖藻类监测数据再与合适的其他水生生物群落, 如无脊椎动物, 包括物理和化 学测量的监测数据结合应用时最有价值.

\section{4 结语}

在 21 个湖泊中, 富营养化湖泊的底栖藻类现存量和底栖硅藻细胞密度均相对较高. 不同营养型湖泊的 底栖硅藻群落结构特征不同, 中营养湖泊的底栖硅藻种类数和多样性指数相对较高, 同时存在多个优势种, 其中极细微曲壳藻是这些湖泊的共同优势种; 中-富营养型湖泊以曲壳藻属的种类占优势; 富营养湖泊的多 样性指数相对较高; 重富营养化湖泊的底栖硅藻种类数和多样性指数低, 小形异极藻占优势.

\section{5 参考文献}

[ 1 ] Kohler J. Long-term response of a shallow, moderately flushed lake to reduced external phosphorus and nitrogen loading. Freshwater Biology, 2005, 50:1639-1650.

[ 2 ] McCormick PV. Periphyton as a potential phosphorus sink in the Everglades Nutrient Removal Project. Ecological Engineering, 2006, 27 : 279-289.

[ 3 ] 于 丹. 湖湾效应对长江中游湖泊水生植物多样性的影响. 生态学报, 1996, 16(5): 476-483.

[ 4 ] Yang XD, Anderson NJ, Dong XH et al. Surface sediment diatom assemblages and epilimnetic total phosphorus in large, shallow lakes of the Yangtze floodplain: their relationships and implications for assessing long-term eutrophication. Freshwater Biology, 2008, 53:1273-1290.

[ 5] 董旭辉, 羊向东, 王 荣. 长江中下游地区湖泊富营养化的硅藻指示性属种. 中国环境科学, 2006,26(5): $570-574$.

[6] American Public Health Association. APHA Standard methods for the examination of water and waste water. 19th edn. 
Washington DC, 1995 : 214-278.

[ 7 ] Steinman AD, Lamberti GA. Biomass and pigments of benthic algae. In: Hauer R, Lamberti GA eds. Methods in stream ecology. NY: Academic Press, 1996: 295-313.

[ 8 ] Barber HG, Haworth EY. A guide to the structure of the diatom frustule. Freshwater Biological Association, Biological Publication, 1981.

[ 9 ] Krammer K, Lange-Bertalot H. Süßwasserflora von Mitteleuropa Bacillariophyceae. Stuttgart: Gustav Fischer Verlag, 1986-1991.

[10] Guach HG. Multivariate analysis in community ecology. London: Cambridge University Press, 1982: 115-214.

[11] Lowe RL, Pan Y. Benthic algal communities and biological monitors. In: Stevenson RJ, Bothwell ML, Lowe RL eds. Algal ecology: Freshwater benthic ecosystems. San Diego: Academic Press, 1996: 705-739.

[12] Fairchild GW, Lowe RL, Richardson WT. Algal periphyton growth on nutrient-diffusing substrates: an in situ bioassay. Ecology, 1985, 66:465-472.

[13] Bennion HA. diatom-phosphorus transfer function for shallow, eutrophic ponds in southeast England. Hydrobiologia, 1994, 275 : 391-410.

[14] Lorch HJ, Ottow JCG. Scanning electron microscopy of bacteria and diatoms attached to a submerged macrophyte in an increasingly polluted stream. Aquatic Botany, 1986, 26:377-384.

[15] Stevenson RJ, Bothwell ML, Lowe RL et al. Algal ecology. San Diego:Academic Press, 1996:10-260.

[16] Nather Khan IS. Effect of urban and industrial wasters on species diversity of the diatom community in a tropical river, Malaysia. Hydrobiologia, 1991, 224 :175-184.

[17] Schŏnfelder I. Relationships between littoral diatoms and their chemical environment in northeastern German lakes and rivers. Joural Phycology, 2002, 38:66-82.

[18] Huston M. A general hypothesis of species diversity. American Naturalist, 1979, 113: 81-101.

[19] Cattaneo A. Periphyton in lakes of different trophy. Canadian Journal of Fisheries and Aquatic Sciences, 1987,44 : 296-303.

[20] Sommer U. Benthic microalagal diversity enhanced by spatial heterogeneity of grazing. Oecologia, 2000, 122 :284-287.

[21] Guzkowska MA, Gasse F. Diatoms as indicators of water quality in some English urban lakes. Freshwater Biology, 1990, $23: 233-250$.

[22] Irvine K. The EC water framework directive and monitoring lakes in the Republic of Ireland. Freshwater Forum, 2001, 16 : $48-64$. 